Journal of Computer Science 2 (2): 191-193, 2006

ISSN 1549-3636

(C) 2006 Science Publications

\title{
ISSP: New Designed Software Package to Enhance E-Learning Approach
}

\author{
${ }^{1}$ Ibrahiem M. M. El Emary and ${ }^{2}$ Hussain F. Sindi \\ ${ }^{1}$ Faculty of Engineering, Amman Al Ahliyya University, Amman, Jordan \\ ${ }^{2}$ Faculty of Science, Computer Science Department, King Abdulaziz University, Jeddah, Kingdom of Saudi Arabia
}

\begin{abstract}
The objective of this study was to present a new software tool assists in enhancing Elearning approach. The presented system is called Instructor- Student Software Package (ISSP). The proposed ISSP contains three main modules: firstly, the lecturing module which is designed to help instructor create lecture notes. Secondly, examination module which is designed to help instructor creates exams available over LAN. Thirdly, students grade book module which is a well defined database to hold student grades and information concerning instructor. So, the work presented here my concern all instructors who are looking for software to help all their tasks computerized, taking advantages of computer accuracy and effort/time utilization in the education field.
\end{abstract}

Key words: ISSP, FTP, SQL server2000, VB.NET, visual studio 7.1.NET 2003

\section{INTRODUCTION}

In view point of advancing the learning process using computerized approaches, there are two techniques support this requirement. The first one is called E-learning which refers to learning that is delivered or enabled via electronic technology. It encompasses learning delivered via a computer- based training, a range of technologies such as: Internet, television, Videotape and Intelligent Tutoring Systems. The second one is known as blended learning which is a term getting a lot of play right now, particularly in the corporate training space. It refers to the use of more than one learning medium, usually a combination of instructor-led learning with computer tools. The effectiveness of a blended approach is not new in K-12 and higher education where it has been the context in which most e-learning takes place ${ }^{[1-3]}$.

Our main objective of this work is to present a software package with a collection of tools and mediums. These tools are really helpful for instructor and student as well. ISSP is a complete package supported with well defined database to help instructor to get it all in one richly featured interface. The proposed ISSP can be considered as an e-learning tool with enhancement of blended learning approach. In this approach, both instructor-led and computer multimedia are used in parallel to help student get the whole picture clear. Moreover, the instructor won't be force to print exams and revolve results in the hard old fusion way, all he has to do is to search for needed files for lectures notes over web (A FTP search engine is one of the recommendations for future extension) and write the best questions for the course (An information bank for questions is another recommendation as a future work) and let the software do the rest of the process.
Finally, the proposed ISST supports the following goals in e-learning:

1. Creating a complete software package and tools to help instructor doing all desired activities which in turn will push the education process completely in positive direction and make it faster, easer and productive.

2. Our software package help instructor getting a really worthiness from PC and minimize his focus on explaining the complicated concepts and theories for any course, which can be easily explained by 30 seconds video. The presented software aims to make blended learning more common for every K-12 schools, colleges and universities students. This will help students get advantages of PC and get the whole picture clear in any field.

\section{ASSUMPTIONS AND DEVELOPMENT ENVIRONMENT OF ISSP SYSTEM}

Experimentally, we assume that many files presented as a material is in fact e-books and power point presentation and according to that, to minimize instructor efforts we make an application which can open all common presentation and multimedia files in its original format and let instructor save all these files in one shareable file provided to all students for viewing. Also experimentally, we assume that most exams are multiple choices and True/False, according to that we try to help instructor to create multi form exam of this model and provide it over LAN.

We use Visual Studio 7.1.NET 2003 as a development environment because of the wide ranges of technologies and platforms that .NET environment can interoperate over. We use VisualBasic.NET language for writing code over all .NET environments.

Corresponding Author: Ibrahiem M. M. El Emary, Faculty of Engineering, Amman Al Ahliyya University, Amman, Jordan 
Also, we start to adopt the new technology, which is the programmer nightmare. Other developing tools are used such as: Microsoft SQL server 2000 and Microsoft Office Visio 2003. Other languages are used like ASP, SQL and XHTML ${ }^{[4-7]}$.

\section{ISSP SYSTEM REQUIREMENTS}

Here, we deal with three types of system requirements given by the following:

Lecturing system requirements: This type of requirement assumes the following:

* The system allow instructor to open all common presentation files and multimedia files.

* The system allows instructor to save all selected files in one shareable file for publishing or distribution over LAN.

* The system allows students to open the file created above and inspect all files attached.

Examination system requirements: This type of requirement assumes the following:

* The system allows instructor to create new multiform exam, add question and publish file for printing and examination over LAN.

* The system allows students to take exams on lab

* The system can get all student grades after they submit exam and put the results after submit exam and put the results in the grade book database.

Grade book system requirements: This type of requirements assumes the following:

* The system allows instructor to add his own courses, view all information about these courses in printout report.

* The system allows instructor to view student grads come from submitted examination forms and update database according to these grades.

* The system allows instructor to view statistics and charts about grade book and student grades.

\section{HIERARCHICAL STRUCTURE OF ISSP SYSTEM}

Now, we describe and explain the main components that construct our ISSP as well as the major functions that is offered by each one ${ }^{[8-10]}$. These components are:

Lecturing system: It's the most helpful tool in our system aims to assist instructor to create lectures notes and supplementary resources including e-books, multimedia and other defined references. This will help him the best he can and to have it all in one file which is shared with student minimizing the effort that the student will have to get these notes.
Examination system: It's the most effective tool in our system. The main function of it is to create a welldesigned multiform exam for a course and to make exam available for all students over LAN, then students' grade will be automatically saved in well defined grade book database to be handled after that for statistics.

Grade book system: It's the most keep worry-away tool in our system. It is a database for grades that can be modified by specific supplementary tools to create the best normal distribution for class grades.

\section{ISSP SYSTEM IMPLEMENTATION PHASES}

Here, we present the various phases that express the design process of the proposed ISSP System. These phases are represented by the following:

Lecturing system module: This is the first component in the system. It is responsible for giving the instructor the ability to open on line Web files in a built in Web browser. Any important diagram can be included in the lecture file and view it using lecturing system. The system has the ability to deny any added existed file. Microsoft office can be added and viewed using built in viewers. All video and audio files may be added to lecturing system and played. After adding all files to the lecture, the instructor have the ability to save it using our own extension (*.1sf) to a shared folder to be accessed by student over LAN. Lecturing files (*.1sf) created by instructor can be opened by student for viewing as a lecture note.

Examination and grade book: Examination system is the second component of the system, it is supposed to generate multi forms and publish it and then students can take the exam over LAN. Firstly, the instructor must login to the system with registered profile or make new profile. In the instructor info tab, the instructor can view his own courses details or add/delete specific course from his profile. In student info tab, the instructor may add students to his courses and view all of them .In the exam generator tab, the instructor generates exams for his courses including exams details. Here, the instructor add all questions to the exam, including True/False questions and multiple choice questions with specific mark for each correct answer. After publishing exam, students can take the exam over LAN, with their own ID and password; if the student is not registered he cannot take the exam. In the exam form, the student checks the correct answer and then grade the exam. In grade book tab, the instructor can view students' grade and all statistics regarding the exam. 


\section{CONCLUSION AND FUTURE WORKS}

In our ISSP system, we decided to adopt system Acquirement analysis cycle, mainly examine the most commonly used software applications world wide for presentation and examination, to get the benefits of all these application in our work. The most common files for lectures was Microsoft office files in addition to common acrobat PDF file, Rich text file, Audio and Video files. All common picture files and of course Internet files. All these files are opened by lecturing system. Also, in examination system we adopt the most common question types true/false and multiple choices. It is used to help instructor to publish exam to shared folder. This exam will be only available for students registered in the course.

The following points are some recommendations for future work:

* An integrated Internet search engine will be very helpful for both instructor and student to get the best results of our work. Internet search engine will help both instructor and student get the benefits of the Internet and search for files and web sites for supplementary material e-libraries, e-books references.

* An online information bank web service for questions is another recommendation for this work. This will help instructor find the best questions covering the material from internet and always make the best newly updated exams for the best benefits for students and instructors.
* An interactive website accompanying web services is the final recommendation for this work this website well helps students find the answer of any question.

\section{REFERENCES}

1. Susan, C. An E-learning Primer. Raytheon Interactive.

2. E-learning Interoperability Standards. Sun Micro System.

3. John, E. E-learning: Emerging Issues and Key Trends. Australia National Training Authority.

4. David, C. and R. Crowder, 2000. Macromedia Dream Weaver 3. Sybex.

5. Alex, K., 2000. SQL Server 2000 Weekend Crash Course. Microsoft Corporation.

6. Robert, B.D. The Book of Visual Studio .NET for Developers. Willian Pollock.

7. Eric, S. Add. NET Primer. Microsoft Corporation.

8. Molley, E.H., 1998. Web by Design the Complete Guide. Sybex.

9. Deitel, D. and Nieto, 2001. E- Business and ECommerce: How to Program. Prentice Hall.

10. Deitel, D. and Nieto, 2002. Internet and World Web: How to Program. Sec. Edn. Prentice Hall. 